\title{
Voltammetric microsensor using PEDOT modified gold electrode \\ for the simultaneous assay of ascorbic and uric acids
}

Fadhila SEKLI-BELAIDI ${ }^{\mathrm{a}}$, Pierre TEMPLE-BOYER ${ }^{\mathrm{b}, \mathrm{c}}$, Pierre GROS ${ }^{\mathrm{a} *}$

aUniversité de Toulouse

Laboratoire de Génie Chimique UMR CNRS/INP/UPS 5503

Université Paul Sabatier

31062 Toulouse cedex FRANCE

Fax : $33561556139 \quad$ e-mail : gros@chimie.ups-tlse.fr

${ }^{\mathrm{b} C N R S}$ - LAAS, 7 avenue du colonel Roche, F-31077 Toulouse, France

'Université de Toulouse; UPS, INSA, INP, ISAE; LAAS, F-31077 Toulouse, France

\begin{abstract}
A voltammetric microsensor has been developed for the simultaneous assay of ascorbic (AA) and uric (UA) acids in aqueous solution. The electrode surface has been modified by means of electropolymerized conductive poly(3,4-ethylenedioxythiophene) PEDOT organic films. The electrocatalytic activity of the interface was dependent on the electropolymerization parameters inducing change in the structure and the morphology of the resulting polymer. The PEDOT thickness was optimized in order to maximize the peak potential separation between both acids oxidation to more than $400 \mathrm{mV}$. By using differential pulse voltammetry (DPV), the sensitivity of the microsensor was $0.87 \mu \mathrm{A} \mu \mathrm{M}^{-1} \mathrm{~cm}^{-2}$ and $4.05 \mu \mathrm{A} \mu \mathrm{M}^{-1} \mathrm{~cm}^{-2}$ for AA and UA respectively. The later was sensible to the presence of AA in the mixture, making evidence of the catalytic mechanism of UA regeneration. The calibration curves were linear in

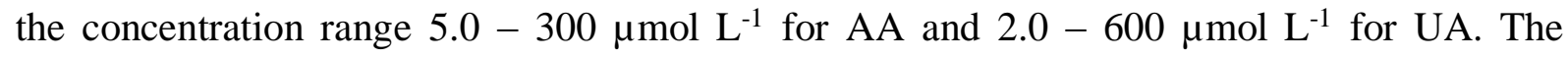
detection limits were $2.5 \mu \mathrm{mol} \mathrm{L} \mathrm{L}^{-1}$ and $1.5 \mu \mathrm{mol} \mathrm{L} \mathrm{L}^{-1}$ respectively. The sensor response was unmodified in the presence of the major electroactive biomarkers. The application of the PEDOT modified microsensor to the analysis of human blood serum was evaluated.
\end{abstract}

Keywords: electrochemical microsensor; PEDOT film; electrocatalytic behavior; ascorbic and uric acids assay. 


\section{1- Introduction}

Ascorbic acid (AA) and uric acid (UA) are both present in most of the biological fluids (plasma, serum, urine, tears, cerebrospinal fluids). At physiological levels, AA is a powerful water soluble antioxidant. It plays a key role in protecting living cells against oxidative injury and has been used clinically for the treatment and prevention of scurvy, common cold, mental illness, cancer and AIDS [1-4]. In the reverse, extreme AA levels can cause gastric irritation, diarrhea and renal problems [2]. The role of UA in conditions associated with oxidative stress is not entirely clear. While commonly regarded as an indicator of gout, epidemiological studies suggest that high UA levels in serum represent a risk factor for cardiovascular diseases [5], uric acid stones [6] and Lesch-Nyhan syndrome [7]. Both ascorbic and uric acids are useful in the monitoring of oxidative stress and moreover may be considered as biochemical markers in a lot of pathologies (neonatal hypoxia, coronary heart diseases...). Thus the selective and convenient detection of AA and UA is very important for biological researches as well as for routine analysis. This explains the numerous methods dedicated to their qualitative and quantitative determination.

Usual procedures for the quantitative determination of AA and UA are generally based on enzymatic methods [8], spectrofluorometry [9], HPLC analysis [10] or capillary electrophoresis [4]. However these methods suffer from costly materials and complex experimental protocols, require sample pretreatment and are generally time consuming. In the last two decades, electrochemical procedures have been greatly employed due to their advantages such as simplicity, low cost, fast analysis and good selectivity [11]. Moreover, microelectrodes present some unique features that make their use advantageous as electrochemical sensors, i.e. enhanced mass transport rate of electroactive species to the electrode surface, reduced double-layer capacitance and less susceptibility to ohmic drop [12]. 
These characteristics make it possible to perform analysis in short time scales and in relative resistive media with enhanced sensitivity [13-14]. Furthermore measurements can be done without any added electrolyte and steady state currents are obtained without stirring the solution. However, a major problem is that AA and UA require generally high overpotentials on usual non-modified bare electrodes. Furthermore both acids are in these conditions oxidized at very close potentials which make their simultaneous detection and quantitative determination difficult [15].

Various approaches have been attempted to solve these problems. Chemically modified electrodes have been particularly developed to discriminate between the electrochemical responses of AA and UA oxidation. Several electrode modification processes have been tested, using highly oxidized metal electrodes [16], metal electrodeposition [17], metal complexes [18,19], electrochemical reduction of diazonium salts [20], mesoporous silica [21], single [22] or multiwalled carbon nanotubes [23], self-assembled thiol monolayer [24], ionexchange Nafion membrane [25] or conducting polymers like poly vinyl alcohol [26], polypyrrole [27] or luminol [28] for measurements in rat brain [29] or in human urine and serum samples [30]. All these studies allowed the simultaneous detection and determination of AA and UA under similar concentrations [31-33] or the assay of UA in samples containing a large excess of AA [34-36]. The analytical performances of these modified electrodes are listed in Table 1.

Concerning electrochemically generated polymers, attention has been devoted since the mid1990s to poly(3,4-ethylenedioxythiophene) (PEDOT) [37] and its derivatives [38,39]. These polymers induce uniform and adherent polymer films on most of electrode materials, show quite high conductivity in their oxidized state, present a good stability in aqueous electrolytes and above all biocompatibility with biological media [40]. Moreover PEDOT was found to be 
resistant to fouling by the AA oxidation products [41], thus indicating PEDOT to be very promising in the design of amperometric sensors. Surprisingly works devoted to the detection of UA and AA by means of PEDOT modified electrodes are very scarce. In most of them AA and/or UA are considered as interfering species, particularly for the assay of dopamine [4245]. To our knowledge the only paper dealing with the simultaneous detection of UA and AA was from Kumar et al. [41]. In this study UA was assayed in the presence of AA in large excess (in the ratio 1:1000), which does not reflect the healthy human situation (the concentration of AA in blood serum being one order of magnitude lower than that of UA in physiological conditions $[4,46])$. Consequently AA was only detected and not assayed while its quantification represents a task of interest as well important as UA in clinical analysis. The aim of our work is then to evaluate PEDOT modified electrodes to selectively detect and simultaneously determine ascorbic and uric acids in aqueous solution.

Many studies have focused on the influence of the electropolymerization conditions on the morphological, structural and physical properties of PEDOT films [37,47-53]. In contrast, only a few studies have been concerned with the role of the PEDOT polymerization conditions on the amperometric response of the resulting sensors. In particular, to the best of our knowledge works dealing with the influence of PEDOT electropolymerization parameters on the electrochemical detection and the simultaneous assay of AA and UA has not been reported so far. In this paper the electrochemical behavior of the modified electrode has been highlighted depending on the electrochemical parameters used for the voltammetric PEDOT deposition (potential range, potential scan rate). In addition, the influence of the experimental conditions (monomer concentration, polymer film thickness) on the analytical performances of the resulting sensor is discussed. 


\section{2- Experimental}

\subsection{Chemicals}

3,4-ethylenedioxythiophene (EDOT) was purchased from Aldrich. Ascorbic acid (AA), uric acid (UA), dopamine, xanthine, hypoxanthine, glutamic acid, cysteine, N-Acetyl-L-cysteine (NAC) and $\beta$-D glucose were purchased from Sigma. Tetrabutylammonium perchlorate (TBAPC), potassium dihydrogenophosphate $\mathrm{KH}_{2} \mathrm{PO}_{4}$, di-potassium hydrogenophosphate $\mathrm{K}_{2} \mathrm{PHO}_{4}$ and acetonitrile were purchased from Acros. All reagents were of analytical grade and used as received. The aqueous solutions were prepared with doubled distilled water. High pure nitrogen was used for deaeration.

\subsection{Materials}

All electrochemical experiments were performed with an Autolab Metrohm potentiostat (Eco-Chimie) interfaced to a microcomputer and using the GPES 4.9 software. A threeelectrode system was used for all the experiments. A $50 \mu \mathrm{m}$ diameter gold wire was purchased from Goodfellow (Lille, France) and used as working electrode. Microelectrodes were fabricated and characterized according to the procedure described by Ruffien-Ciszak et al. [54]. The protocol involved glass capillaries from Clark Electromedical Instruments (Phymep, Paris, France), a microelectrode puller (Model PC 10) and a microgrinder (Model EG44) purchased from Narishige (London, UK). A $1 \mathrm{~mm}$ diameter platinum wire $(1 \mathrm{~cm}$ length) was used as auxiliary electrode. All potentials reported in the text are referred to a saturated calomel reference electrode (SCE) $\left(\mathrm{Hg} / \mathrm{Hg}_{2} \mathrm{Cl}_{2} / \mathrm{KCl}_{\text {sat }}\right)$ connected to the cell by a Luggin capillary.

\subsection{Preparation of PEDOT-modified gold microelectrodes}


The procedure of PEDOT electrodeposition on gold microelectrodes was similar to that reported by Kumar et al [41]. A gold disk microelectrode was polished with alumina slurry and rinsed with distilled water. The polished surface was then pretreated by cycling the electrode potential between $-0.88 \mathrm{~V}$ and $1.5 \mathrm{~V}$ for 10 minutes at $10 \mathrm{mV} \mathrm{s}^{-1}$ in $20 \mathrm{~mL}$ deaerated acetonitrile containing $0.1 \mathrm{~mol} \mathrm{~L}^{-1} \mathrm{TBAPC}$ as supporting electrolyte. Deaeration was obtained by purging the solution with nitrogen during 10 minutes; moreover a nitrogen atmosphere was maintained over the solution during the experiments. The electropolymerization was performed in deaerated acetonitrile containing different concentrations of EDOT monomer and $0.1 \mathrm{~mol} \mathrm{~L}^{-1}$ TBAPC. The polymer was synthesized by cycling the electrode potential between $-0.88 \mathrm{~V}$ and a variable upper potential (see results). The scanning potential rate, the monomer concentration and the number of potential cycles were also variable. The modified electrode was then rinsed with acetonitrile and distilled water successively to remove any physically adsorbed monomer. This modified electrode is hereafter referred to as $\mu \mathrm{Au}-$ PEDOT.

\subsection{Electrochemical detection of AA and UA}

The $\mu$ Au-PEDOT was immersed in a three-electrode cell where a nitrogen flux was constantly maintained. Experiments were performed in $10 \mathrm{~mL}$ deaerated phosphate buffer solution (PBS) pH 7.0 containing well-known amounts of AA and/or UA. Two electrochemical methods were applied, i.e. cyclic voltammetry (CV) and differential pulse voltammetry (DPV). Cyclic voltammograms (CVs) were plotted between $-0.2 \mathrm{~V}$ and $0.6 \mathrm{~V}$ (unless otherwise indicated), with a potential scan rate of $50 \mathrm{mV} \mathrm{s}^{-1}$, thus avoiding the reduction of water and the oxidation of gold as well as the overoxidation of PEDOT which would irreversibly result in a non-conducting polymer [55]. For differential pulse voltammograms (DPVs), the potential waveform was optimized with respect to the 
determination of AA [56]: pulse amplitude $50 \mathrm{mV}$, step potential $6 \mathrm{mV}$, pulse time $119 \mathrm{~ms}$, interval time 1s, potential scan rate $6 \mathrm{mV} / \mathrm{s}$. The particular features of the microelectrodes made it possible to perform experiments without stirring the solution.

\subsection{Blood serum analysis}

Human blood serum was kindly given by the Laboratoire de Biochimie from Hôpital Rangueil - Toulouse and stored at $4^{\circ} \mathrm{C}$ before being used. Owing to the microelectrode size, experiments were realized in $250 \mu \mathrm{L}$ sample volume. Furthermore no electrolyte was added and the sample was undiluted and not stirred. Electrochemical measurements were performed by DPV using the same potential waveform described in $\S 2.4$. The sample was left to come at room temperature before the analysis.

\section{Results and discussion}

\subsection{PEDOT electrodeposition}

Fig. 1 shows five successive cyclic voltammograms recorded during EDOT electropolymerization. The oxidation of the monomer began at about $1 \mathrm{~V}$ on the first potential cycle and the anodic current reached a peak value at $1.3 \mathrm{~V}$. In the reverse scan, the current decreased with a crossover at about $1.2 \mathrm{~V}$. By analogy with metal deposition process, this "nucleation loop" reveals a nucleation process of the polymer film [57]. On the following cycles, the oxidation reaction was shifted to more cathodic potential values. This phenomenon is related to the fact that the oligomers produced can be oxidized more easily than the monomer [58]. The anodic current increased from cycle to cycle consequently to the growth of a conductive PEDOT film, thus increasing the apparent surface of the active electrode. The voltammograms also revealed a quasi-reversible signal at a potential close to $-0.3 \mathrm{~V}$ corresponding to the redox activity of the polymer. Both anodic and cathodic peak currents 
increased with the number of potential cycles, thus depending on the amount of polymer synthesized on the electrode surface.

\subsection{Electrochemical behavior of AA and UA on PEDOT modified electrode}

Fig. 2 shows cyclic voltammograms recorded with a bare-gold microelectrode (Fig. 2.A) and a $\mu \mathrm{Au}$-PEDOT modified electrode (Fig. 2.B) immersed in an equimolar solution of AA and

UA $1 \mathrm{mmol} \mathrm{L}-1$. The PEDOT modified electrode was obtained by cycling the potential of the gold microelectrode 5 times between $-0.88 \mathrm{~V}$ and $1.5 \mathrm{~V}$ with a scan rate of $100 \mathrm{mV} \mathrm{s}^{-1}$ in the electropolymerization solution containing EDOT $10 \mathrm{mmol} \mathrm{L}^{-1}$. Whatever the electrode, no significant signal was observed in PBS pH 7.0 except for the electro-oxidation of gold starting at about $0.8 \mathrm{~V}$. The oxidation of AA and UA on the unmodified electrode resulted in a broad anodic current. Two overlapped waves were present with half-wave potentials $\mathrm{E}_{1 / 2}$ close to $0.4 \mathrm{~V}$ and $0.6 \mathrm{~V}$ for $\mathrm{AA}$ and $\mathrm{UA}$ respectively. These results are in agreement with previous works making evidence that both antioxidant species cannot be detected selectively on bare electrodes [15]. In contrast, two well-defined oxidation signals were recorded with the $\mu \mathrm{Au}-$ PEDOT electrode. The anodic peak potentials for AA and UA were shifted to more negative values, i.e. $-0.037 \mathrm{~V}$ and $0.33 \mathrm{~V}$ respectively, making the sensor less sensitive to possible interfering species when used in real media. The potential difference was more than $300 \mathrm{mV}$, thus allowing the simultaneous detection of both species with the same modified electrode. The peak separation was attributed to different surface accumulations by means of electrostatic and hydrophobic attractions. Several papers reported that conducting polymers coated on electrode surfaces contain a distribution of reduced and oxidized forms [59-60]. Ascorbic acid $\left(\mathrm{pK}_{\mathrm{a}}=4.1\right)$ being in its anionic form at physiological $\mathrm{pH}$ interacts electrostatically with the positively charged oxidized regions of the polymer. On the other hand, Schöp and Kößmehl [61] reported that the reduced form of polythiophene was 
hydrophobic in nature. Uric acid $\left(\mathrm{pK}_{\mathrm{a}}=5.4\right)$ is more hydrophobic than AA and is therefore concentrated in the PEDOT matrix because of hydrophobic interactions. These interactions certainly explain also why the amperometric responses at $\mu \mathrm{Au}-\mathrm{PEDOT}(0.17$ and $0.39 \mathrm{~mA}$ $\mathrm{cm}^{-2}$ ) were 2 and 3.5 fold higher for AA and UA $1 \mathrm{mmol} \mathrm{L}^{-1}$ respectively compared to those obtained on the unmodified electrode, thus improving the sensitivity of the sensor. Anyway the PEDOT modified electrode clearly demonstrates a catalytic activity for the oxidation of both antioxidant species.

Similar experiments were performed by differential pulse voltammetry (Fig. 2.C). Results have led to the same conclusions, i.e. a broad non exploitable amperometric response with the bare gold microelectrode and two distinct anodic peaks when using the $\mu$ Au-PEDOT. By optimizing the potential waveform [56], it was possible to shift the peak potentials to even more cathodic values, i.e. $-0.039 \mathrm{~V}$ and $0.246 \mathrm{~V}$ for AA and UA oxidation respectively. Furthermore the response sensitivity was sensibly improved compared to that recorded by $\mathrm{CV}$, i.e. 0.23 and $0.62 \mathrm{~mA} \mathrm{~cm}^{-2}$ for $\mathrm{AA}$ and $\mathrm{UA} 1 \mathrm{mmol} \mathrm{L}^{-1}$ respectively. DPV was then chosen in all the following electrochemical detection experiments.

\subsection{Influence of the electropolymerization parameters}

\subsubsection{PEDOT film thickness}

As the improved detections of AA and UA result from particular interactions with PEDOT, investigation have been done concerning the effect of the PEDOT film thickness. The later was varied consecutively to the number of potential cycles between $-0.88 \mathrm{~V}$ and $1.5 \mathrm{~V}$ at 100 $\mathrm{mV} \mathrm{s}^{-1}$ in TBAPC-acetonitrile containing EDOT $10 \mathrm{mmol} \mathrm{L}^{-1}$. However it was easier to control the polymer thickness by means of the total charge consumed during the electropolymerization step since the charge consumed during one potential cycle did not keep a constant value from cycle to cycle. Different charge densities ranging from 1 to $34 \mathrm{mC} \mathrm{cm}{ }^{-2}$ 
have been tested. Voltammograms were then recorded in PBS pH 7.0 containing AA and UA $1 \mathrm{mmol} \mathrm{L}-1$. Fig. 3 shows the analytical performances obtained for AA oxidation in terms of peak potential (Fig. 3.A) and of peak current density (Fig. 3.B). From these results two major conclusions can be given: increasing the polymer film thickness improves the heterogeneous electron transfer rate of AA oxidation since the peak potential shifted to more cathodic values; the active surface area of the electrode increases with the polymer growth since the peak current density corresponding to AA oxidation also increased. In consequence both selectivity and sensitivity of the sensor were improved. Similar results have been obtained with UA (data not shown). The evolution of the oxidation peak potentials for both antioxidant species as a function of the electropolymerization charge is indicated in Table 2. The most important shift in the oxidation potential occurred with charge densities ranging from 1 to $12 \mathrm{mC} \mathrm{cm}^{-2}$. In this later case, the potential difference reached $380 \mathrm{mV}$. Increasing further the thickness of the film did not improve significantly the selectivity of the sensor. Previous studies have shown that thin films are compact while the polymer becomes more ordered and conjugated with thickness, inducing a higher conductivity [37]. It was also suggested that the increase of the PEDOT thickness makes the polymer more hydrophilic [53]. Since AA and UA are hydrophilic compounds, their interactions with the film would thus be amplified. It can be concluded from the above results that the morphology and structural properties of electrogenerated PEDOT films have considerable effects on the analytical performances of the sensor. In order to improve significantly the selectivity of the modified electrode without synthesizing a too thick polymer film, all the following experiments have been performed with an electropolymerization charge of $12 \mathrm{mC} \mathrm{cm}^{-2}$.

\subsubsection{Monomer concentration}


Several experiments were performed by changing the concentration of the monomer from 2.5 mmol L ${ }^{-1}$ to $20 \mathrm{mmol} \mathrm{L}^{-1}$. All the electrodes were realized by cycling the electrode potential between $-0.88 \mathrm{~V}$ and $1.5 \mathrm{~V}$ with a total electropolymerization charge of $12 \mathrm{mC} \mathrm{cm}^{-2}$. Table 3 shows the analytical performances in terms of peak potential and of peak current density for the oxidation of AA and UA $1 \mathrm{mmol} \mathrm{L}^{-1}$ by DPV. Whatever the modified electrode, AA and UA oxidations occur approximately at the same potentials, i.e. $-90 \pm 3 \mathrm{mV}$ and $240 \pm 9 \mathrm{mV}$ respectively. On the contrary, the sensitivity for both substrates was strongly dependent on the composition of the polymerization solution: the lower the monomer concentration, the higher the electrocatalytic activity of PEDOT film. This result is in agreement with previous studies showing that high monomer concentrations produce loose, poorly conducting films containing significant amounts of soluble oligomers whereas low monomer concentrations improve both the cohesion and the conductivity of the polymer [37, 47].

\subsubsection{Electropolymerization potential range}

Previous works have shown that the morphology of PEDOT films depends on the potential range used for electropolymerization: it changes from globular to fibrous morphology by increasing the upper potential limit with a significant enhancement of the porosity of PEDOT film [48]. In order to show the influence of the potential range on the analytical performances of the voltammetric sensor, the following experiments were performed. Several modified electrodes were elaborated by changing the upper potential boundary from $1.2 \mathrm{~V}$ to $2 \mathrm{~V}$. They were then tested in an equimolar solution of AA and UA $1 \mathrm{mmol} \mathrm{L}^{-1} \mathrm{pH}$ 7.0. Results are shown in Fig. 4. When the upper potential was less than $1.2 \mathrm{~V}$ (curve a), a large oxidation signal was observed for the oxidation of AA and UA. This behavior was quite similar to that observed with the unmodified electrode, even if the curve was slightly shifted to cathodic potentials in the former case. When the upper potential reached $1.3 \mathrm{~V}$ (curve b), two well 
defined and separate peaks were recorded at $-0.1 \mathrm{~V}$ and $0.23 \mathrm{~V}$. Further increase of the upper potential to $1.5 \mathrm{~V}$ did not significantly improve the detection selectivity for both acids (curves c and d). However both peak current densities increased with the upper potential boundary, thus improving the sensitivity of the sensor. When the upper electropolymerization potential was beyond $1.5 \mathrm{~V}$, a second anodic peak appeared at about $1.6 \mathrm{~V}$ during the electropolymerisation step, corresponding to the overoxidation of the polymer [48] (result not shown). Overoxidation of PEDOT is known to reduce irreversibly its conductivity [55]. Consistently the DPVs of the resulting modified electrode highlighted that the peak current densities corresponding to the oxidation of AA and UA decreased (Figure 4, curve e). Finally by increasing the upper potential to $2 \mathrm{~V}$ during the electropolymerization step induced a serious degradation of the polymer because the solvent was oxidized in the same time. In order to keep the electroactivity of the polymer while maximizing the sensitivity of the resulting sensor, the upper potential was limited to $1.5 \mathrm{~V}$.

\subsubsection{Potential scan rate during electropolymerization}

Fig. 5 shows the DPVs obtained for AA and UA oxidation when adopting various potential scan rates ranging from 50 to $400 \mathrm{mV} \mathrm{s}^{-1}$ during the voltammetric PEDOT electropolymerization. In all cases, the amount of charge used was kept constant. For potential scan rates lower than $250 \mathrm{mV} \mathrm{s}^{-1}$, the lowest oxidation potential and the highest amperometric response for both acids were obtained with the highest potential scan rate. Increasing the scan rate resulted in higher electrodeposition currents (results not shown). The electropolymerization reaction rate increased in the same way, thus improving the film porosity [51]. Consequently the interaction between the polymer and both acids was improved. For potential scan rate higher than $250 \mathrm{mV} \mathrm{s}^{-1}$ the analytical performances of the resulting microsensor were not significantly improved. For instance the increase of the 
amperometric signal due to UA oxidation was only $17.5 \%$ (from 1.78 to $2.09 \mathrm{~mA} \mathrm{~cm}^{-2}$ ) when changing the potential scan rate from 250 to $400 \mathrm{mV} \mathrm{s}^{-1}$ during the electropolymerisation step. This result is probably due to the difficulty to obtain an homogenous and ordered polymer film with such high scan rate.

\subsection{Analytical performances}

The analytical performances of the $\mu \mathrm{Au}$-PEDOT modified electrode for AA and UA assays were evaluated with the optimized values of the electropolymerization parameters, i.e. potential range from $-0.88 \mathrm{~V}$ to $1.5 \mathrm{~V}$, potential scan rate $250 \mathrm{mV} \mathrm{s}^{-1}$, monomer concentration $2.5 \mathrm{mmol} \mathrm{L}{ }^{-1}$, electropolymerization charge density $12 \mathrm{mC} \mathrm{cm}^{-2}$. Fig. 6.A and Fig. 6.B exhibit the DPVs recorded under increasing concentrations of AA and UA respectively. The resulting calibration curves are also shown (inset). For AA, The peak current density increased linearly with the concentration in the range $5.0-300 \mu \mathrm{mol} \mathrm{L}-1$ with a sensitivity of $0.87 \mu \mathrm{A} \mu \mathrm{M}^{-1} \mathrm{~cm}^{-2}$ and a detection limit of $2.5 \mu \mathrm{mol} \mathrm{L} \mathrm{L}^{-1}(\mathrm{~S} / \mathrm{N}=3)$. The UA oxidation current density varied linearly with the concentration in the range $2.0-600 \mu \mathrm{mol} \mathrm{L}^{-1}$ with a sensitivity of $3.06 \mu \mathrm{A}$ $\mu \mathrm{M}^{-1} \mathrm{~cm}^{-2}$ and a detection limit of $1.5 \mu \mathrm{mol} \mathrm{L}^{-1}(\mathrm{~S} / \mathrm{N}=3)$. The relative standard deviations (R.S.D.) were $1.1 \%$ and $1.4 \%$ for 3 successive measurements of AA and UA $1 \mathrm{mM}$ respectively. These analytical performances were compared to those obtained on different modified electrodes and reported recently in the literature (Table 1). To the best of our knowledge, the PEDOT modified voltammetric microsensor presented in this paper induced the highest separation peak potential and one of the greatest sensitivities for UA assay. Comparison concerning the sensitivity for AA was not so easy since AA was introduced in large excess and consequently not systematically assayed in most of the papers published. Anyway these analytical performances are well suited to the assay of both acids in biologic fluids like blood serum, as well as under physiological conditions (the physiological 
concentrations in blood serum are between 34 and $79 \mu \mathrm{mol} \mathrm{L}-1$ for AA and between 180 and $420 \mu \mathrm{mol} \mathrm{L}-1$ for UA $[4,46])$ as in the presence of one of the two acids at high concentrations. The DPVs were also recorded in the presence of both acids in the mixture solution (Fig. 6.C). Both calibration curves exhibited a linear variation of the peak current as a function of the concentration of the corresponding antioxidant specie (not shown). The resulting sensitivity was roughly unchanged for AA whereas it increased to $4.05 \mu \mathrm{A} \mu \mathrm{M}^{-1} \mathrm{~cm}^{-2}$ for UA. This enhancement of the sensitivity of the microsensor for UA in the presence of AA reveals an EC' mechanism resulting from a chemical reaction in solution coupled to the electrochemical step [62]. The apparent standard potential of the (ascorbyl radical / ascorbate ion) redox system being lower than that of the (alloxan / urate) one $(0.28 \mathrm{~V}$ and $0.59 \mathrm{~V}$ vs SCE at pH 7.0 respectively [63-64]), a spontaneous oxidoreduction reaction between AA and the UA oxidation product takes place, thus regenerating the reduced form of UA at the vicinity of the modified electrode surface. Further experiments have been performed in the laboratory to highlight this mechanism. For example, addition of $200 \mu \mathrm{L}$ of a solution of AA $8 \mathrm{mmol} \mathrm{L}^{-1}$ in $10 \mathrm{~mL}$ of a solution of UA $300 \mu \mathrm{mol} \mathrm{L} \mathrm{L}^{-1}$ (corresponding to a final concentration of AA equal to $156 \mu \mathrm{mol} \mathrm{L}-1$ ) induced an amplification of $14.5 \%$ of the anodic current corresponding to UA oxidation recorded near $0.3 \mathrm{~V}$ by DPV. If the coupled chemical reaction was not present, the later would be constant or would decrease slightly due to the dilution of the initial solution. This was for instance the case when aliquots contained only buffered solution without AA. The amplification of the current was not due to the polymer since similar results were observed when the experiments were realized on a non-modified gold microelectrode: using the same protocol, the increase of the anodic current recorded at $0.8 \mathrm{~V}$ was each time about three fold the increase that was expected by considering only the additional current due to the introduction of $\mathrm{AA}$ in solution. In consequence, in contrast with several previous published papers indicating that AA induced no interference in the assay of UA (sometimes in 
contradiction with the experimental results presented, see for example ref $[26,28,33])$, an obvious change was observed in our case in the UA oxidation current depending on whether AA was present in the sample or not. Consequently two different protocols have to be practically adopted depending on the composition of the samples: in the case where all samples contain AA (particularly if in large excess), the assay of UA would induce no bias provided that the calibration curve is performed in the presence of AA. In the case where AA is not present or is in concentration similar to that of UA, AA has to be assayed before UA, the calibration curve of UA taking account of the presence or the absence of AA.

\subsection{Interfering species}

In order to be used further in real samples the voltammetric sensor has been tested in the presence of the main common substances co-existing in the same concentration range and which could interfere with the detection of AA and UA in biological fluids. In this respect the effect of dopamine, xanthine, hypoxanthine, glutamic acid, NAC, cysteine, glucose and albumin was examined. Fig. 7 shows the DPVs obtained with a solution containing all these species. Compared to the curve obtained with only AA and UA (Fig. 2.C) no change was observed in the oxidation peak potentials of both antioxidant species. Furthermore, their amperometric responses were not affected except in the presence of xanthine. In this later case the peak current density corresponding to UA oxidation increased during the second potential sweep only when the potential reached $0.64 \mathrm{~V}$ in the first scan, thus allowing the electrochemical oxidation of xanthine into uric acid [61]. In consequence, the potential range of the $\mu$ Au-PEDOT voltammetric sensor has to be reduced from $-0.3 \mathrm{~V}$ to $0.5 \mathrm{~V}$ in order to obtain selective and reliable results for the assay or AA and UA in complex media. In this potential range, glutamic acid was not detected and glucose presented no electrochemical 
activity. Finally the presence of albumin induced a slight positive shift of about $30 \mathrm{mV}$ in the oxidation peak potentials of all the electrochemically detected species.

\subsection{Blood serum analyses}

The application of the $\mu \mathrm{Au}-\mathrm{PEDOT}$ modified electrode to the detection of AA and UA in human blood serum was evaluated. Figure 8 shows preliminary results obtained by DPV in $250 \mu \mathrm{L}$ undiluted sample (curve a). The voltammogram showed two well defined and separate peaks recorded at $-0.03 \mathrm{~V}$ and $0.20 \mathrm{~V}$. It was verified that these anodic signals corresponded to the oxidation of AA and UA respectively by successively adding both acids in the sample (curves $b$ and $c$ ). This confirms that the voltammetric PEDOT modified microsensor is suitable to detect simultaneously submicromolar AA and UA concentrations in real samples. Nevertheless the peak potentials were not exactly the same as those recorded in standard aqueous solutions (Figure 6.C). This was certainly due to the matrix effect in blood serum. Works are now in progress to quantitatively assay both antioxidant species taking into account the EC' mechanism of UA regeneration.

\section{Conclusion}

Modification of gold microelectrode surface by means of PEDOT electropolymerization has proved to be efficient to elaborate a voltammetric sensor for the assay of AA and UA. Optimization of the major electropolymerization parameters (monomer concentration, potential range, potential scan rate, polymer film thickness) induced analytical performances (in terms of sensitivity, concentration range and detection limit) in agreement with the concentration of both species in biological fluids. As reported in literature studies, these parameters determine to a large extent the structure and the electrocatalytic properties of the polymer. The optimized selectivity and sensitivity of the sensor have been reached with 
parameters inducing ordered and porous matrix with high electrical conductivity. The $\mu \mathrm{Au}-$ PEDOT electrode thus exhibits a potential and persistent electrocatalytic behavior which makes possible to consider it as a convenient probe for the assay of many compounds of biological importance. Works are in progress in our laboratory to evaluate the performances of such sensor in real physiological fluids.

\section{Acknowledgements}

The authors would like to thank Professor Maurice Comtat from the Laboratoire de Génie Chimique and Benjamin Huerta Ortega from Vivelys Company for fruitful scientific discussions, Laure Latapie from the Laboratoire de Génie Chimique for technical support and Anne Galinier from the Laboratoire de Biochimie - Hôpital Rangueil Toulouse for blood serum gift.

\section{References}

[1] O. Arrigoni, M. Tullio, Biochim. Biophys. Acta. 1569 (2002) 1-9.

[2] H. K. Choi, X. Gao, G. Curhan, Arch. Inter. Med. 169 (2009) 502-507.

[3] D. T. Alexandrescu, C. A. Dasanu, C. L. Kauffman, Clin. Exp. Dermatol. 34 (2009) $811-$ 814.

[4] M.C. Polidori, W. Stahl, O. Eichler, I. Niestroj, H. Sies, Free Rad. Biol. Med. 30 (2001) $456-462$.

[5] M. H. Alderman, Curr. Opin. Pharmacol. 2 (2002) 126-130.

[6] G. C. Curhan, E. N. Taylor, J.Urol. 181 (2009) 1721-1723.

[7] H. A. Jinnah, Disease Models \& Mechanisms. 2 (2009) 116-121.

[8] Y. Zhao, X. Yang, W. Lu, H. Liao, F. Liao, Microchim Acta. 164 (2009) 1-6. 
[9] S. L. Feng, J. Wang, X. G. Chen, J. Fan, Spectrochim. Acta, Part A. 61 (2005) 841-844.

[10] Z. Gazdik, O. Zitka, J. Petrlova, V. Adam, J. Zehnalek, A. Horna, V. Reznicek, M. Beklova, R. Kizek, Sensors. 8 (2008) 7097-7112.

[11] S. A. Wring, J. P. Hart, Analyst. 117 (1992) 1215-1229.

[12] R. M. Wightman, D.O. Wipf, in: A. J. Bard, M. Dekker (Eds), Electroanalytical chemistry - Voltammetry at Ultramicroelectrodes, New York and Basel, 1989, Vol 15, pp. 267-363.

[13] T. Hepel, J. Osteryoung, J. Phys. Chem. 86 (1982) 1406-1411.

[14] J. O. Howell, R. M. Wightman, J. Phys. Chem. 88 (1984) 3915-3918.

[15] D. Zheng, J.Ye, L. Zhou, Y. Zhang, C. Yu, J. Electroanal. Chem. 625 (2009) 82-87.

[16] J. Premkumar, S.B. Khoo, J. Electroanal. Chem. 576 (2005) 105-112.

[17] T. Selvaraju, R. Ramaraj, Electrochim. Acta 52 (2007) 2998-3005.

[18] C-X. Li, Y-L. Zeng, Y-J. Liu, C-R. Tang, Anal. Sci. 22 (2006) 393-397.

[19] S. Sharokhian, H. R. Zare-Mehrjardi, Electroanalysis 19 (2007) 2234-2242.

[20] H. M. Nassef, A-E. Radi, C. O’Sullivan, Anal. Chim. Acta 583 (2007) 182-189.

[21] D. Sun, Y. Zhang, F. Wang, K. Wu, J. Chen, Y. Zhou, Sens. Actuators B. 141 (2009) 641-645.

[22] S. Zhu, H. Li, W. Niu, G. Xu, Biosens. Bioelectron. 25 (2009) 940-943.

[23] S. Zhang, M. Xu, Y. Zhang, Electroanalysis 21 (2009) 2607-2610.

[24] C. R. Raj, T. Ohsaka, J. Electroanal. Chem. 540 (2003) 69-77.

[25] H. Jeong, S. Jeon, Sensors. 8 (2008) 6924-6935.

[26] Y. Li, X. Lin, Sens. Actuators B 115 (2006) 134-139.

[27] T.F. Kang, G.L. Shen, R.Q. Yu, Chem. Res. Chin. Univ. 13 (1997) 207-214.

[28] S. A. Kumar, H-W. Cheng, S-M. Chen, Electroanalysis 21 (2009) 2281-2286.

[29] M. Zhang, K. Liu, L. Xiang, Y. Lin, L. Su, L. Mao, Anal. Chem. 79 (2007) 6559-6565. 
[30] S. Shahrokhian, M. Ghalkhani, Electrochim. Acta 51 (2006) 2599-2606.

[31] A.A. Ensafi, M. Taei, T. Khayamian, J. Electroanal. Chem. 633 (2009) 212-220.

[32] P. Kalimuthu, S.A. John, Anal. Chim. Acta. 647 (2009) 97-103.

[33] M.Y. Wang, X.Y. Xu, F. Yang, S.Y. Zhang, X. J. Yang, J. Appl. Electrochem. 38 (2008) $1269-1274$.

[34] P. Kalimuthu, S.A. John, Bioelectrochem. 77 (2009) 13-18.

[35] X. Zhu, X. Lin, Chin. J. Chem. 27 (2009) 1103-1109.

[36] J-B. He, G-P. Jin, Q-Z. Chen, Y. Wang, Anal. Chim. Acta 585 (2007) 337-343.

[37] J. Roncali, Chem. Rev. 92 (1992) 711-738.

[38] L. Groenendaal, F. Jonas, D. Freitag, H. Pielartzik, J. R. Reynolds, Adv. Mater. 12 (2000) 481-494.

[39] L. Groenendaal, G. Zotti, P.-H. Aubert, S.M. Waybright, J.R. Reynolds, Adv. Mater. 15 (2003) 855-879.

[40] N. K. Guimard, N. Gomez, C. E. Schmidt, Prog. Polym. Sci. 32 (2007) 876-921.

[41] S. S. Kumar, J. Mathiyarasu, K. L. Phani, Y. K. Jain, V. Yegnaraman, Electroanalysis. 17 (2005) 2281-2286.

[42] A. Balamurugan, S-M. Chen, Anal. Chim. Acta 596 (2007) 92-98.

[43] V.S. Vasantha, S-M. Chen, J. Electroanal. Chem. 592 (2006) 77-87.

[44] V.S. Vasantha, S-M. Chen, Electrochim. Acta 52 (2006) 665-674.

[45] S. Lupu, A. Mucci, L. Pigani, R. Seeber, C. Zanardi, Electroanalysis. 14 (2002) 519-525.

[46] P. Boulanger, J. Polonovski, F. Tayeau, P. Mandel, G. Biserte, Biochimie Médicale, eight ed., Masson, Paris, 1971.

[47] M.A. Sato, S. Tanaka, K. Kaeriyama, Chem. Soc. Chem. Commun. 11 (1985) 713-714.

[48] S. Patra, K. Barai, N. Munichandraiah, Synth. Met. 158 (2008) 430-435.

[49] M. C. Morvant, J. R. Reynolds, Synth. Met. 92 (1998) 57-61. 
[50] L. Niu, C. Kvarnström, K. Fröberg, A. Ivaska, Synth. Met. 122 (2001) 425-429.

[51] A. I. Melato, M. H. Mendonça, L. M. Abrantes, J. Solid State Electrochem. 13 (2009) 417-426.

[52] H. Randriamahazaka, V. Noël, C. Chevrot, J. Electroanal. Chem. 472 (1999) 103-111.

[53] T. Darmanin, M. Nicolas, F. Guittard, Phys. Chem. Chem. Phys. 10 (2008) 4322-4326.

[54] A. Ruffien-Ciszak, P. Gros, M. Comtat, A.-M. Schmitt, E. Questel, C. Casas, D. Redoules, J. Pharm. Biomed. Anal. 40 (2006) 162-167.

[55] E. Tamburri, S. Orlanducci, F. Toschi, M.L. Terranova, D. Passeri, Synth. Met. 159 (2009) 406-414.

[56] A. Bello, M. Gianneto, G. Mori, R. Seeber, F. Terzi, C. Zanardi, Sens. Actuators, B. 121 (2007) 430-435.

[57] A.J. Downard, D. Pletcher, J. Electroanal Chem. 206 (1986) 147-152.

[58] C. P. Andrieux, P. Audebert, P. Hapiot, J.-M. Saveant, J. Phys. Chem. 95 (1991) 1015810164.

[59] C. R. Martin, L. S. Van Dyke, in: R. W. Murray (Eds), Mass and Charge Transport in Electronically Conductive Polymers, Wiley, New York, 1992, pp. 403-424.

[60] M. E. G. Lyons, in: M. E. G. Lyons (Eds), Charge Percollation in Electroactive Polymers, Electroactive Polymer Electrochemistry Part I, Plenum Press, New York, 1994, pp. 65-116

[61] G. Schöpf, G. Kößmehl, Electrically Conductive Polymers, Springer-Verlag, Germany 1997, p. 80.

[62] A.J. Bard, L.R. Faulkner, Electrochimie : principes, méthodes et applications, Masson, Paris, 1983, p. 486.

[63] G.R. Buettner, B.A. Jurkiewicz, in: E. Cadenas, L. Packer (Eds.), Handbook of antioxidants, M. Dekker, New-York, 1996, pp. 91-115. 
[64] C. Jacob, G.I. Giles, N.M. Giles, H. Sies, Angew. Chem. Int. Ed. 42 (2003) 4742-4758. 
Fig.1. Successive CVs obtained with a $50 \mu \mathrm{m}$ diameter $\mathrm{Au}$ microelectrode in a deaerated 0.1 mol L-1 TBAPC-acetonitrile containing EDOT $10 \mathrm{mmol} \mathrm{L}^{-1}$. Potential scan rate: $100 \mathrm{mV} \mathrm{s}^{-1}$.

Fig.2. (A) and (B): CVs obtained with (A) a $50 \mu \mathrm{m}$ Au microelectrode and (B) a $\mu$ Au-PEDOT modified electrode in PBS pH 7.0 (dotted line) and in an equimolar solution of AA and UA 1 mmol L-1 $\mathrm{pH} 7.0$ (solid line). (C) DPVs recorded with a $50 \mu \mathrm{m}$ Au microelectrode (dotted line) and a $\mu \mathrm{Au}-\mathrm{PEDOT}$ (solid line) in the equimolar AA/UA solution. Electrochemical parameters for CVs and DPVs are indicated in section 2.4.

Fig.3. Effect of the polymerization charge density on (A) the peak potential and on (B) the peak current density recorded for the oxidation of AA $1 \mathrm{mmol} \mathrm{L}^{-1} \mathrm{pH} 7.0$ on a $\mu \mathrm{Au}-\mathrm{PEDOT}$ modified electrode by DPV. The polymerization was performed by cyclic voltammetry between -0.88 and $1.5 \mathrm{~V}$ vs SCE at $100 \mathrm{mV} \mathrm{s}^{-1}$ in $0.1 \mathrm{TBAPC}$-acetonitrile containing EDOT $10 \mathrm{mmol} \mathrm{L}-1$.

Fig.4. DPVs recorded with a $50 \mu \mathrm{m}$ Au microelectrode (dotted line) and with a $\mu$ Au-PEDOT (solid lines) in an equimolar AA/UA solution $1 \mathrm{mmol} \mathrm{L}^{-1} \mathrm{pH} 7.0$ solution. Influence of the upper potential used for the electropolymerization in $0.1 \mathrm{~mol} \mathrm{~L}^{-1}$ TBAPC-acetonitrile containing EDOT $2.5 \mathrm{mmol} \mathrm{L}^{-1}$ : (a) $1.2 \mathrm{~V}$; (b) $1.3 \mathrm{~V}$; (c) $1.4 \mathrm{~V}$; (d) $1.5 \mathrm{~V}$; (e) $1.6 \mathrm{~V}$ vs SCE.

Fig.5. DPVs recorded with a $\mu$ Au-PEDOT in an equimolar AA/UA $1 \mathrm{mmol} \mathrm{L}^{-1} \mathrm{pH} 7.0$. Influence of the potential scan rate used during the electropolymerization between $-0.88 \mathrm{~V}$ and $1.5 \mathrm{~V}$ vs SCE in $0.1 \mathrm{~mol} \mathrm{~L}^{-1} \mathrm{TBAPC}$-acetonitrile containing EDOT $2.5 \mathrm{mmol} \mathrm{L}^{-1}$. (a) 50; (b) 100; (c) 150; (d) 200; (e) 250; (f) $400 \mathrm{mV} \mathrm{s}^{-1}$.

Fig.6. (A) and (B): DPVs recorded with a $\mu$ Au-PEDOT in (A) different AA solutions and in (B) different UA solutions $\mathrm{pH}$ 7.0. Inset: calibration curves. (C): DPV recorded with the modified electrode in mixture solutions containing AA and UA respectively at: (1): 5 and 6 
$\mu \mathrm{mol} \mathrm{L} \mathrm{L}^{-1}$; (2): 17 and 12; (3): 38 and 30; (4): 54 and 50; (5): 69 and 89; (6): 84 and 135; (7): 103 and 181; (8): 122 and 210; (9): 148 and 279; (10): 181 and 396 and (11): 220 and 499 $\mu \mathrm{mol} \mathrm{L}{ }^{-1}$. PEDOT film was electropolymerized between $-0.88 \mathrm{~V}$ and $1.5 \mathrm{~V}$ vs SCE at $250 \mathrm{mV}$ $\mathrm{s}^{-1}$ in $0.1 \mathrm{~mol} \mathrm{~L}^{-1}$ TBAPC-acetonitrile containing EDOT $2.5 \mathrm{mmol} \mathrm{L}^{-1}$.

Fig.7. DPV recorded with a $\mu$ Au-PEDOT in PBS $0.1 \mathrm{~mol} \mathrm{~L}^{-1} \mathrm{pH} 7.0$ containing ascorbic acid $200 \mu \mathrm{mol} \mathrm{L} \mathrm{L}^{-1}$, dopamine $50 \mu \mathrm{mol} \mathrm{L}-1$, uric acid $150 \mu \mathrm{mol} \mathrm{L} \mathrm{L}^{-1}$, xanthine $100 \mu \mathrm{mol} \mathrm{L} \mathrm{L}^{-1}$, hypoxanthine $100 \mu \mathrm{mol} \mathrm{L}{ }^{-1}$, cysteine $200 \mu \mathrm{mol} \mathrm{L}-1$, NAC $100 \mu \mathrm{mol} \mathrm{L}-1$, glutamic acid 500 $\mu \mathrm{mol} \mathrm{L}{ }^{-1}$, glucose $5.5 \mathrm{mmol} \mathrm{L}^{-1}$ and albumin $2 \mathrm{~g} \mathrm{~L}^{-1}$. PEDOT film was electropolymerized between $-0.88 \mathrm{~V}$ and $1.5 \mathrm{~V}$ vs $\mathrm{SCE}$ at $250 \mathrm{mV} \mathrm{s}^{-1}$ in $0.1 \mathrm{~mol} \mathrm{~L}^{-1}$ TBAPC-acetonitrile containing EDOT $2.5 \mathrm{mmol} \mathrm{L}-1$.

Fig.8 DPV recorded with a $\mu$ Au-PEDOT in (a) $250 \mu \mathrm{L}$ undiluted blood serum; (b) addition of AA $19 \mu \mathrm{mol} \mathrm{L} \mathrm{L}^{-1}$; (c) addition of UA $35 \mu \mathrm{mol} \mathrm{L}{ }^{-1}$. PEDOT film was electropolymerized between $-0.88 \mathrm{~V}$ and $1.5 \mathrm{~V}$ vs $\mathrm{SCE}$ at $250 \mathrm{mV} \mathrm{s}^{-1}$ in $0.1 \mathrm{~mol} \mathrm{~L}^{-1}$ TBAPC-acetonitrile containing EDOT $2.5 \mathrm{mmol} \mathrm{L}-1$. 
Table 1. Comparison of the analytical performances of different electrochemical microsensors for the determination of ascorbic (AA) and uric (UA) acids.

\begin{tabular}{cccccccccc}
\hline \multirow{2}{*}{ Ref } & \multicolumn{2}{c}{$\mathrm{E}_{\mathrm{p}} / \mathrm{mV}$ vs SCE } & \multirow{2}{*}{$\Delta \mathrm{E}_{\mathrm{p}} / \mathrm{mV}$} & \multicolumn{2}{c}{$\begin{array}{c}\text { Sensitivity } / \\
\mu \mathrm{A} \mu \mathrm{M}^{-1} \mathrm{~cm}^{-2}\end{array}$} & $\begin{array}{c}\text { Limit of } \\
\text { detection } / \mu \mathrm{M}\end{array}$ & \multicolumn{2}{c}{ Linear range $/ \mu \mathrm{M}$} \\
\cline { 2 - 9 } & $\mathrm{AA}$ & $\mathrm{UA}$ & & $\mathrm{AA}$ & $\mathrm{UA}$ & $\mathrm{AA}$ & $\mathrm{UA}$ & $\mathrm{AA}$ & $\mathrm{UA}$ \\
\hline 16 & 200 & 599 & 399 & - & - & 100 & 0.2 & $100-7000$ & $0.2-60$ \\
17 & -100 & 300 & 400 & - & - & - & 0.01 & $1-40$ & $20-50$ \\
18 & 5 & 320 & 270 & 0.645 & 3.97 & 5 & 0.5 & $9-2000$ & $2-400$ \\
$19^{*}$ & 314 & 400 & 104 & 0.116 & 0.156 & 0.1 & 0.06 & $0.5-100$ & $0.1-100$ \\
20 & 263 & 600 & 337 & 0.167 & 89.32 & 0.3 & 14 & $2-20$ & $150-600$ \\
21 & 0 & 250 & 250 & - & - & 10 & 0.24 & $40-4000$ & $0.5-75$ \\
22 & 13 & 376 & 363 & 0.283 & 84.35 & 5 & 0.2 & $30-400$ & $0.06-10$ \\
$23^{*}$ & - & 252 & - & - & 0.078 & - & 0.17 & - & $3.3-96.3$ \\
24 & 120 & 380 & 260 & 0.382 & 0.741 & - & 1 & - & $1-300$ \\
26 & 6 & 330 & 324 & 7.12 & 24.88 & 7.6 & 0.6 & $10-250$ & $2-50$ \\
$28^{*}$ & 29 & 295 & 266 & excess & 0.06 & - & 2 & - & $30-1000$ \\
$29^{*}$ & 50 & - & - & 0.0048 & - & 40 & - & $100-1000$ & - \\
30 & 270 & 460 & 190 & - & - & 0.5 & 0.08 & $1-80$ & $0.4-100$ \\
31 & 280 & 610 & 330 & 3.50 & 11.46 & 1.43 & 0.016 & $5-240$ & $0.1-18$ \\
32 & 210 & 480 & 270 & 1.41 & 1.91 & - & - & - & - \\
33 & 104 & 327 & 223 & 6.98 & 7.26 & 2 & 2 & $5-160$ & $5-300$ \\
34 & 6 & 410 & 404 & 1.40 & 2.39 & 0.92 & 0.57 & $30-240$ & $10-80$ \\
35 & 3 & 300 & 297 & 0.044 & 0.815 & 15 & 0.18 & $75-3000$ & $0.74-230$ \\
36 & 5 & 300 & 295 & excess & 2.80 & - & 1 & - & $1-50$ \\
41 & -35 & 335 & 370 & excess & 6.76 & - & 1 & - & $1-20$ \\
42 & 100 & 420 & 320 & - & - & - & - & - & - \\
43 & 8 & - & - & 0.169 & - & - & 6 & $300-1500$ & - \\
44 & 100 & 350 & 250 & - & - & - & - & - & - \\
This & -94 & 308 & 403 & 0.875 & 4.05 & 2.5 & 1.5 & $5-300$ & $2-600$ \\
work & & & & & & & & & \\
& & & & & & & & & \\
\hline
\end{tabular}

*In these references sensitivities are expressed in $\mu \mathrm{A} \mu \mathrm{M}^{-1}$ because the surface area of the electrode is not mentioned. 
Table 2. Influence of the PEDOT polymerization charge density on the peak potential for the oxidation of AA and UA $1 \mathrm{mmol} \mathrm{L} \mathrm{LH}^{-1} \mathrm{pH}$ by DPV. PEDOT films were synthesized by cyclic voltammetry between $-0.88 \mathrm{~V}$ and $1.5 \mathrm{~V}$ vs SCE at $100 \mathrm{mV} \mathrm{s}^{-1}$ in $0.1 \mathrm{~mol} \mathrm{~L}^{-1}$ TBAPCacetonitrile containing EDOT $10 \mathrm{mmol} \mathrm{L}^{-1}$.

\begin{tabular}{cccc}
\hline $\mathrm{Q} / \mathrm{mC} \mathrm{cm}{ }^{-2}$ & $\mathrm{EP} \mathrm{AA} / \mathrm{mV}$ vs SCE & Ep UA / mV vs SCE & $\Delta \mathrm{E}_{\mathrm{p}} / \mathrm{mV}$ \\
\hline 0 & 263 & 475 & 212 \\
0.2 & 20 & 357 & 337 \\
0.6 & 0 & 347 & 347 \\
1.2 & -16 & 349 & 365 \\
2.5 & -26 & 352 & 378 \\
6.7 & -42 & 338 & 380 \\
10 & -48 & 322 & 370 \\
12 & -72 & 308 & 380 \\
20 & -80 & 308 & 388 \\
23 & -93 & 308 & 401 \\
34 & -95 & 308 & 403 \\
\hline
\end{tabular}


Table 3. Variation of the peak potential and of the peak current density for the oxidation of AA and UA $1 \mathrm{mmol} \mathrm{L}^{-1} \mathrm{pH} 7.0$ by DPV as a function of the concentration of EDOT monomer in the polymerization solution. PEDOT films were synthesized by cyclic voltammetry between $-0.88 \mathrm{~V}$ and $1.5 \mathrm{~V}$ vs SCE at $250 \mathrm{mV} \mathrm{s}^{-1}$ with a total charge of $12 \mathrm{mC} \mathrm{cm}^{-2}$.

\begin{tabular}{ccccc}
\hline \multirow{2}{*}{$\begin{array}{c}\text { monomer } \\
\text { concentration / mM }\end{array}$} & \multicolumn{2}{c}{$\mathrm{E}_{\mathrm{p}} / \mathrm{mV}$ vs SCE } & \multicolumn{2}{c}{$\mathrm{jp}_{\mathrm{p}} \mathrm{A} \mathrm{M}^{-1} \mathrm{~cm}^{-2}$} \\
\cline { 2 - 5 } 2.5 & $\mathrm{AA}$ & $\mathrm{UA}$ & $\mathrm{AA}$ & $\mathrm{UA}$ \\
\hline 5 & -92 & 246 & 0.275 & 1.43 \\
10 & -91 & 234 & 0.236 & 1.22 \\
20 & -85 & 230 & 0.187 & 0.951 \\
\hline
\end{tabular}




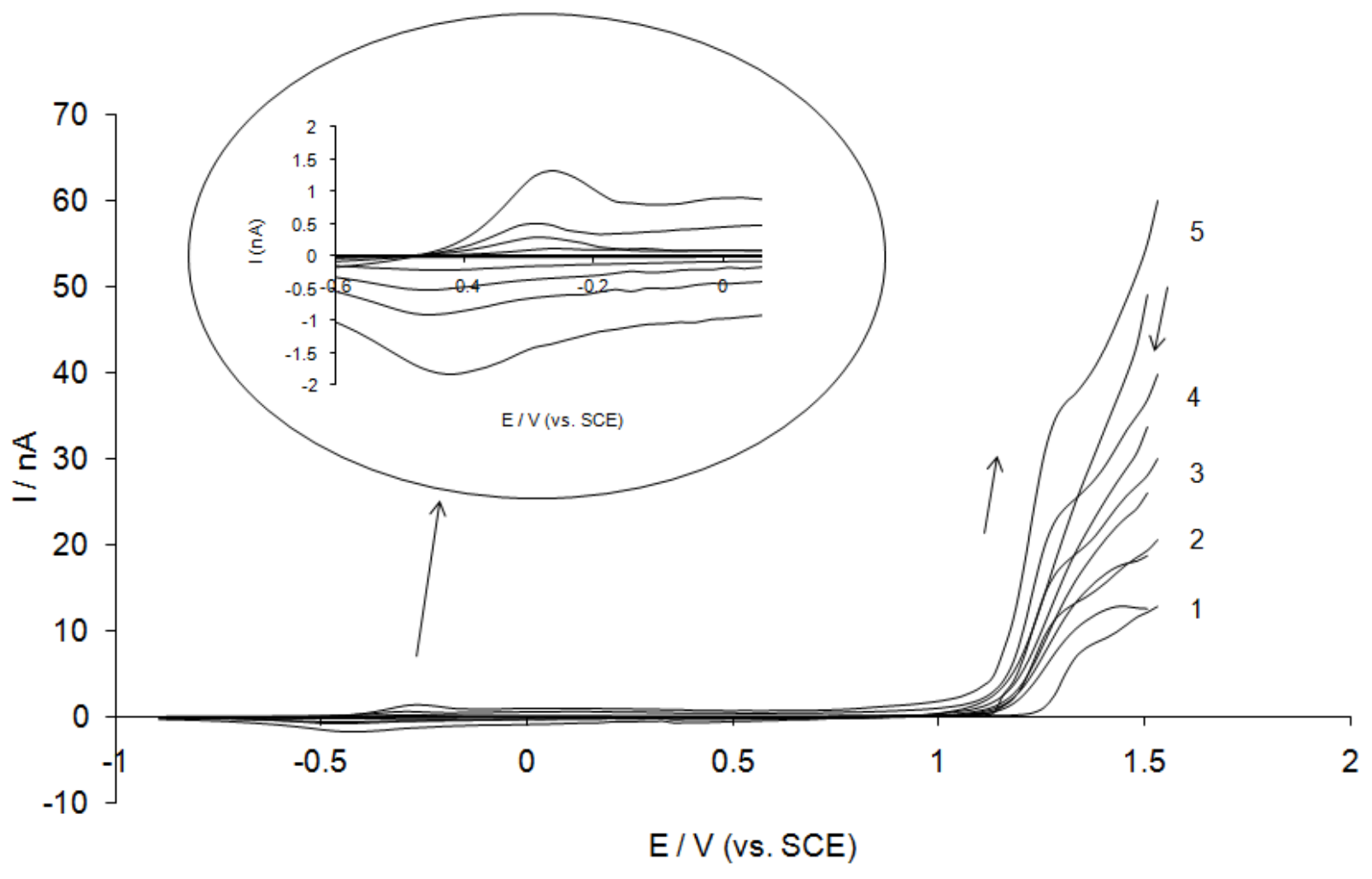

Figure 1. 


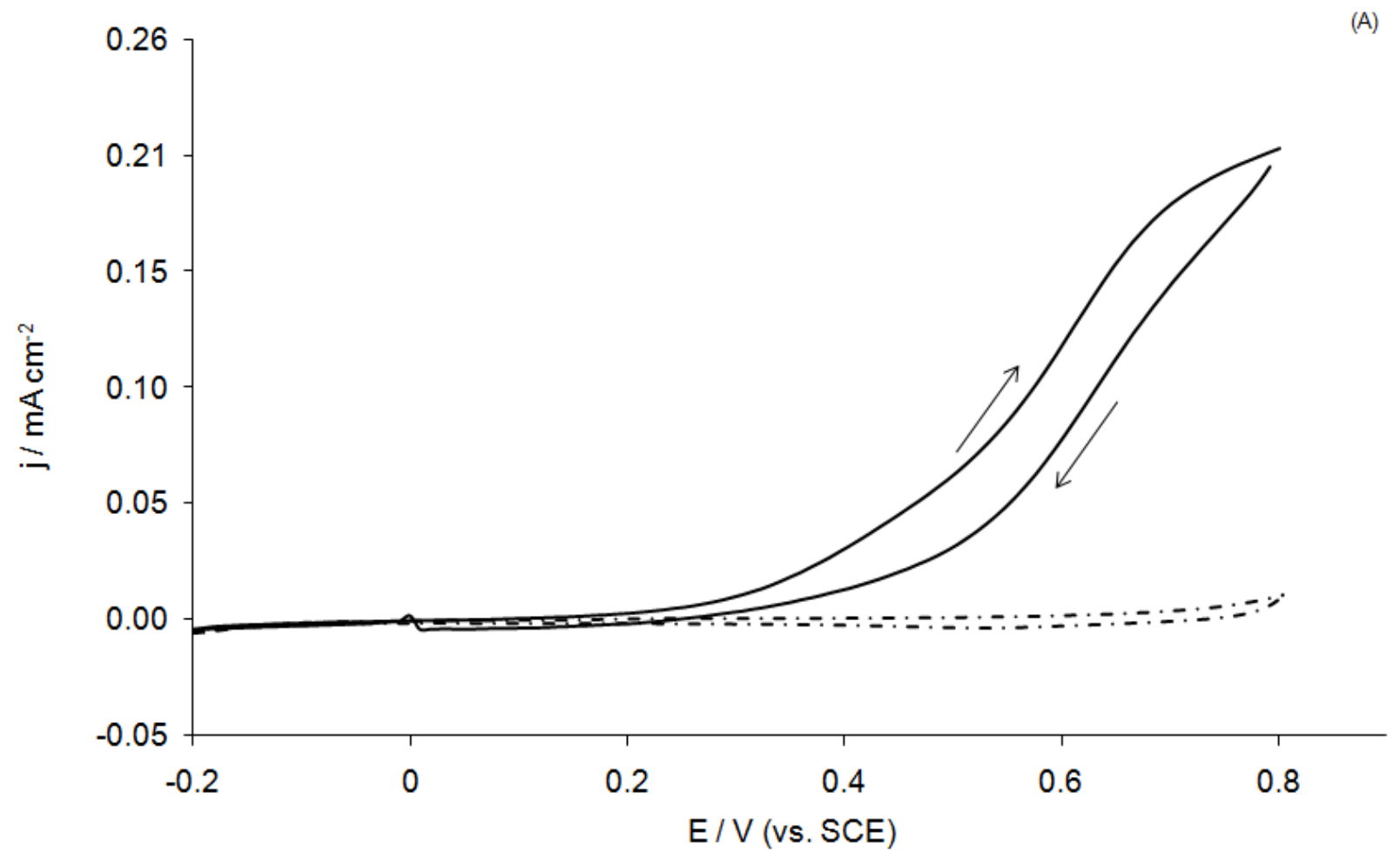

Figure 2A. 


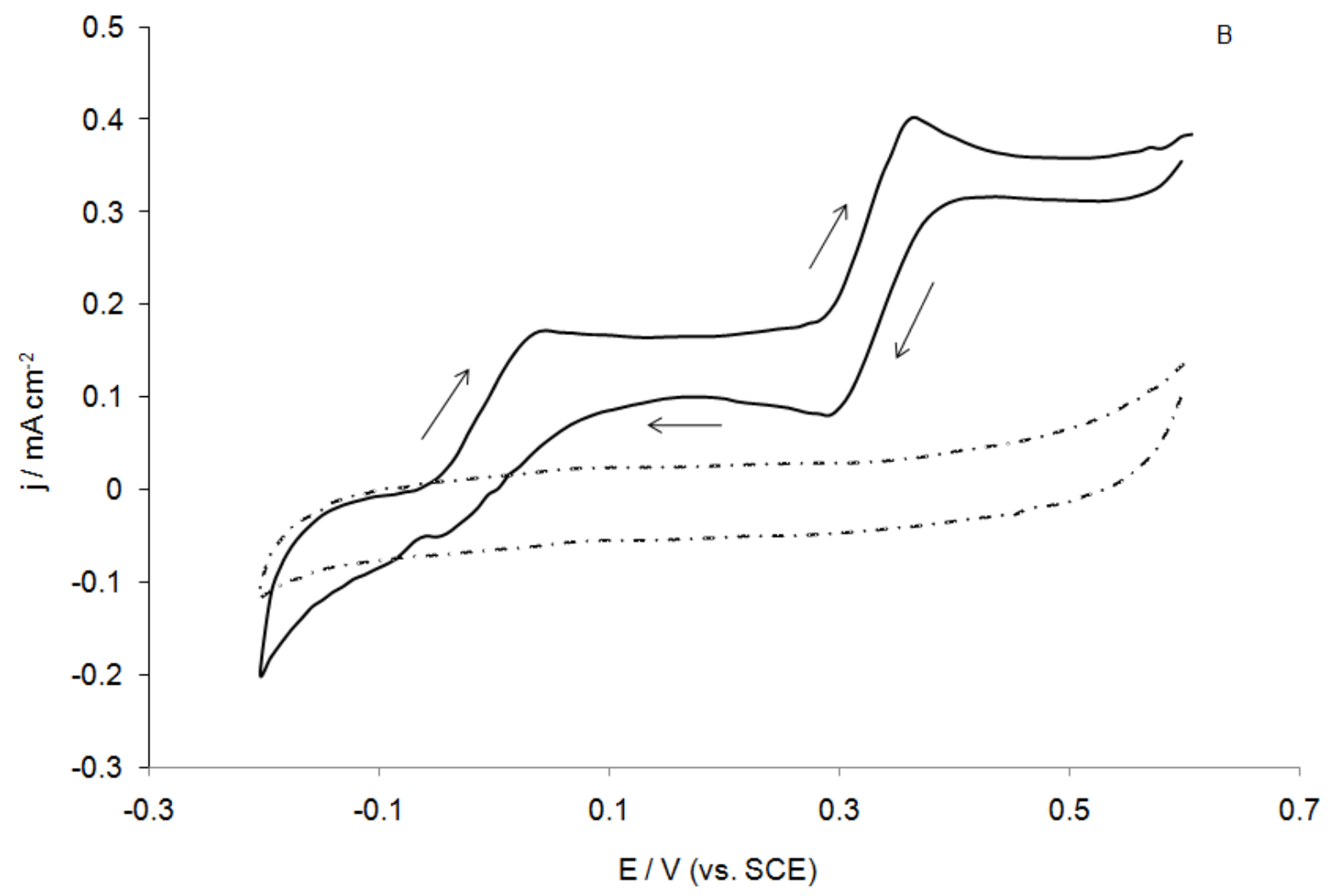

Figure 2B. 


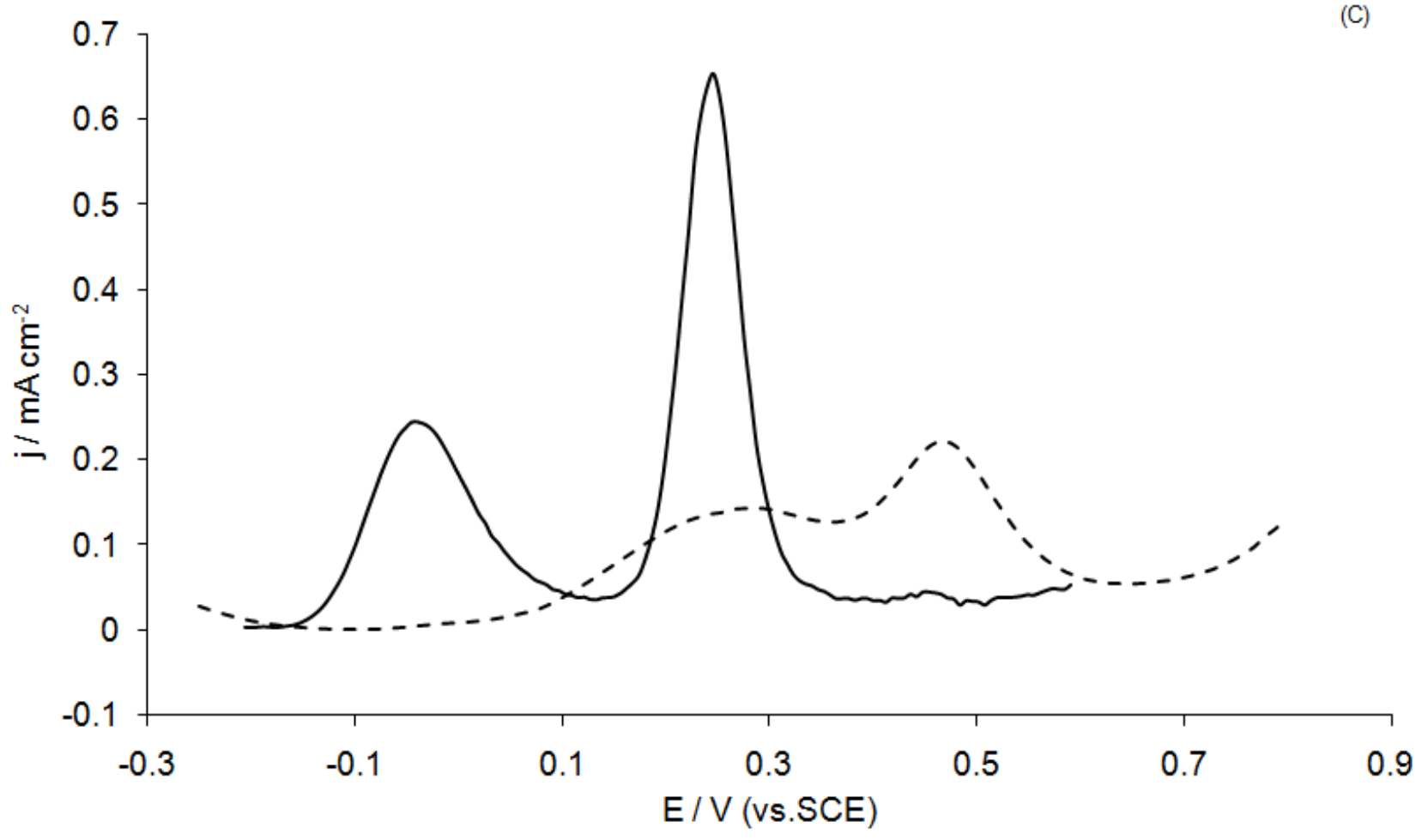

Figure 2C. 


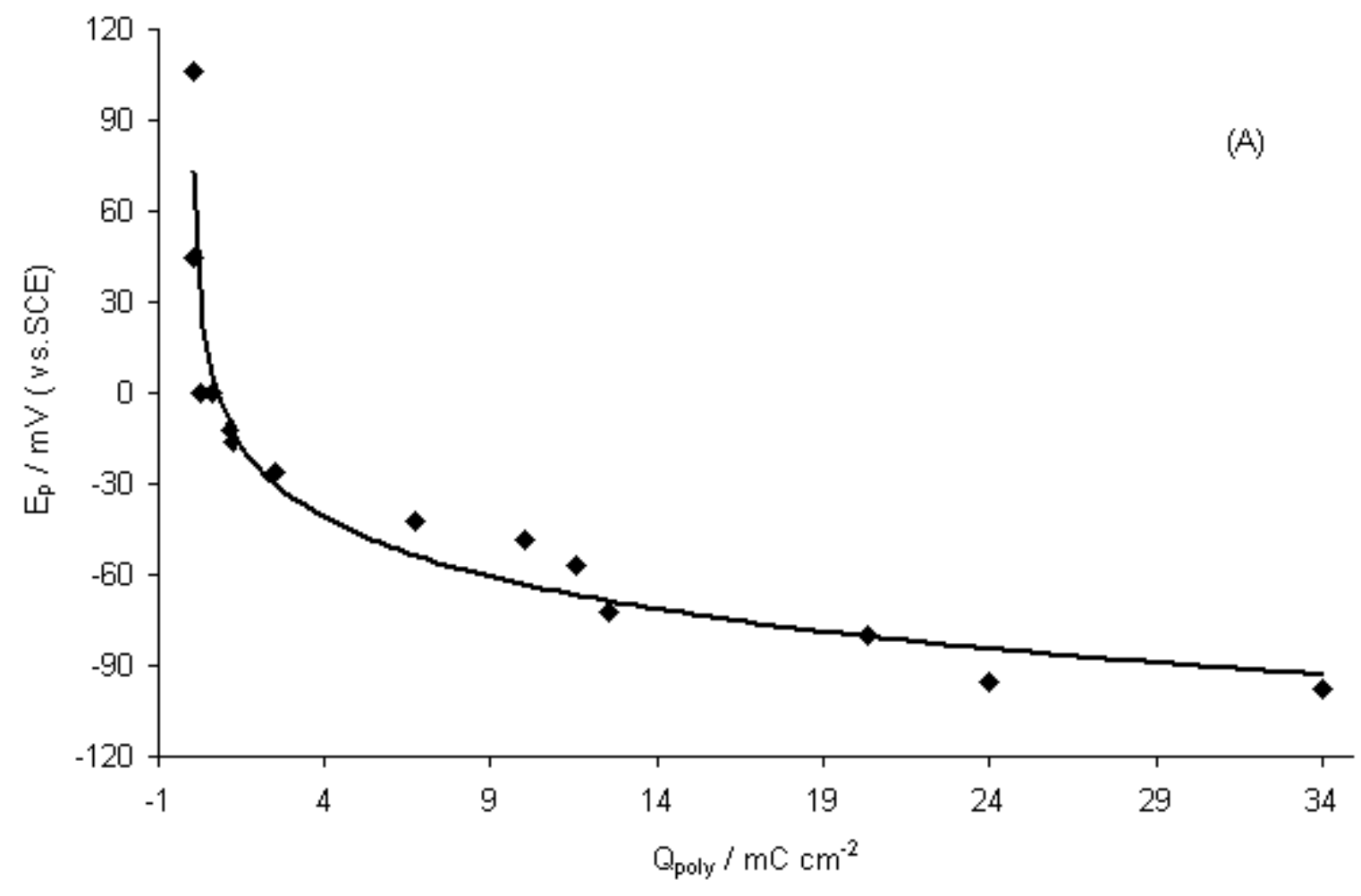

Figure 3A. 


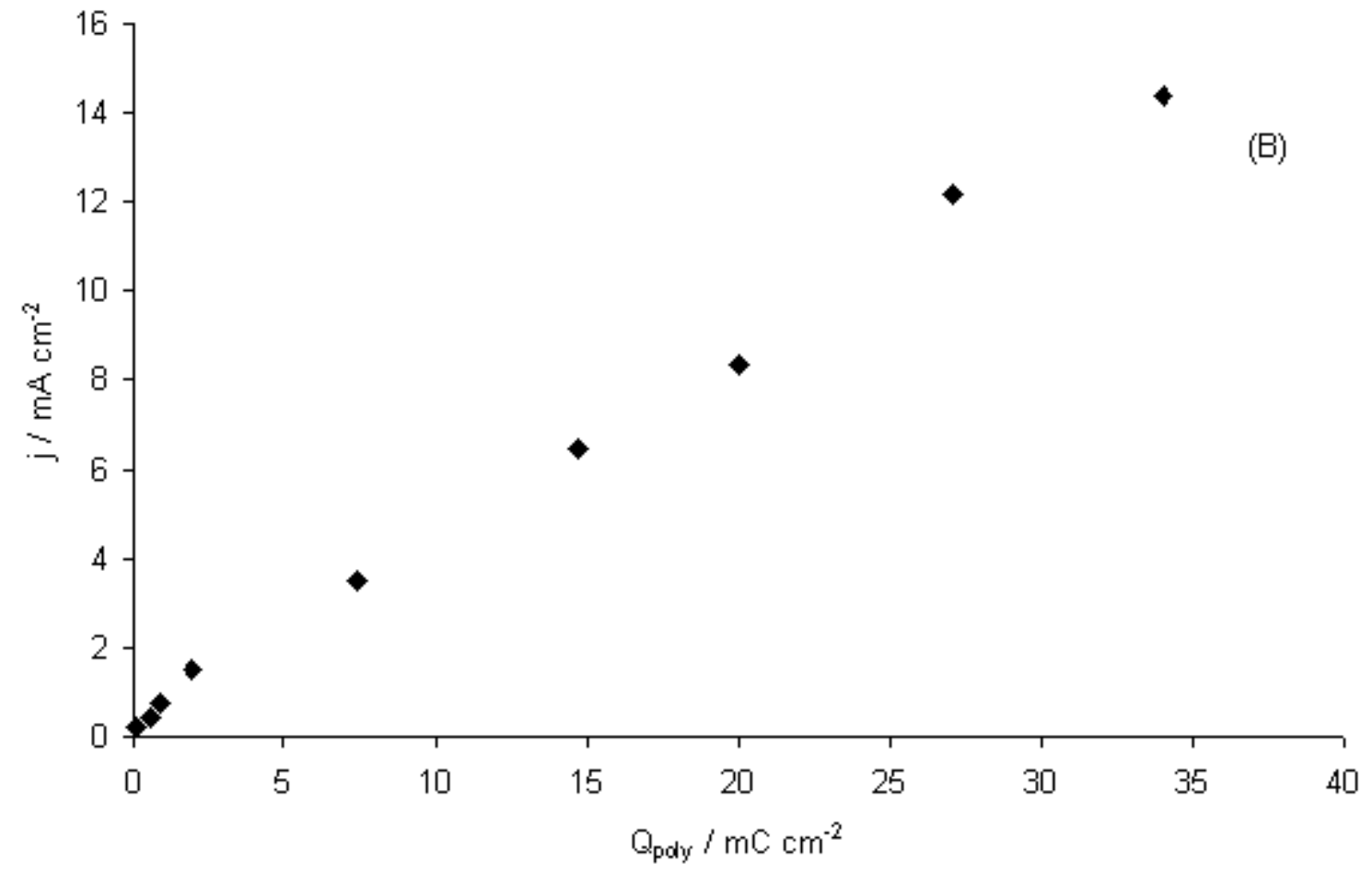

Figure 3B. 


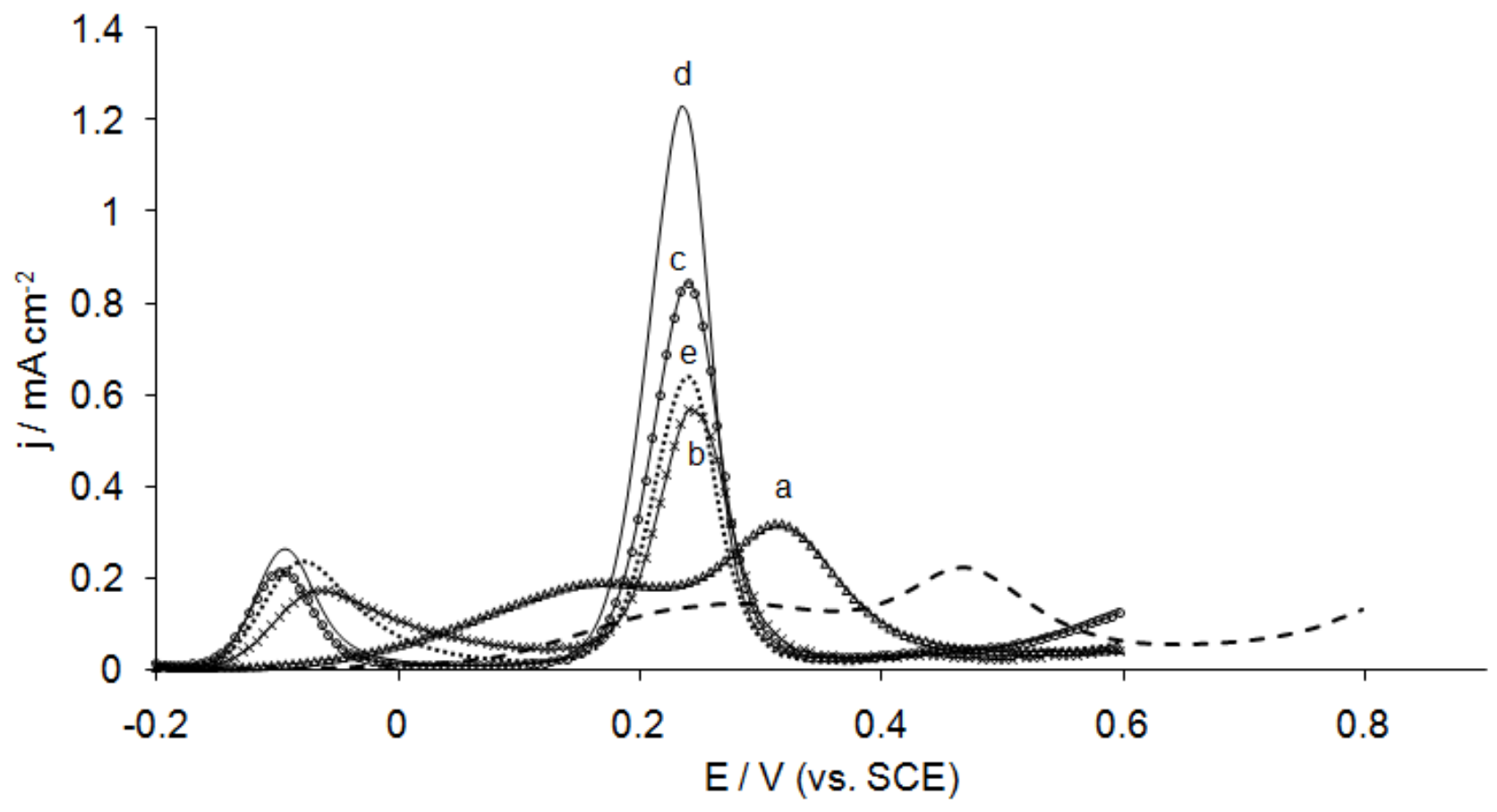

Figure 4. 


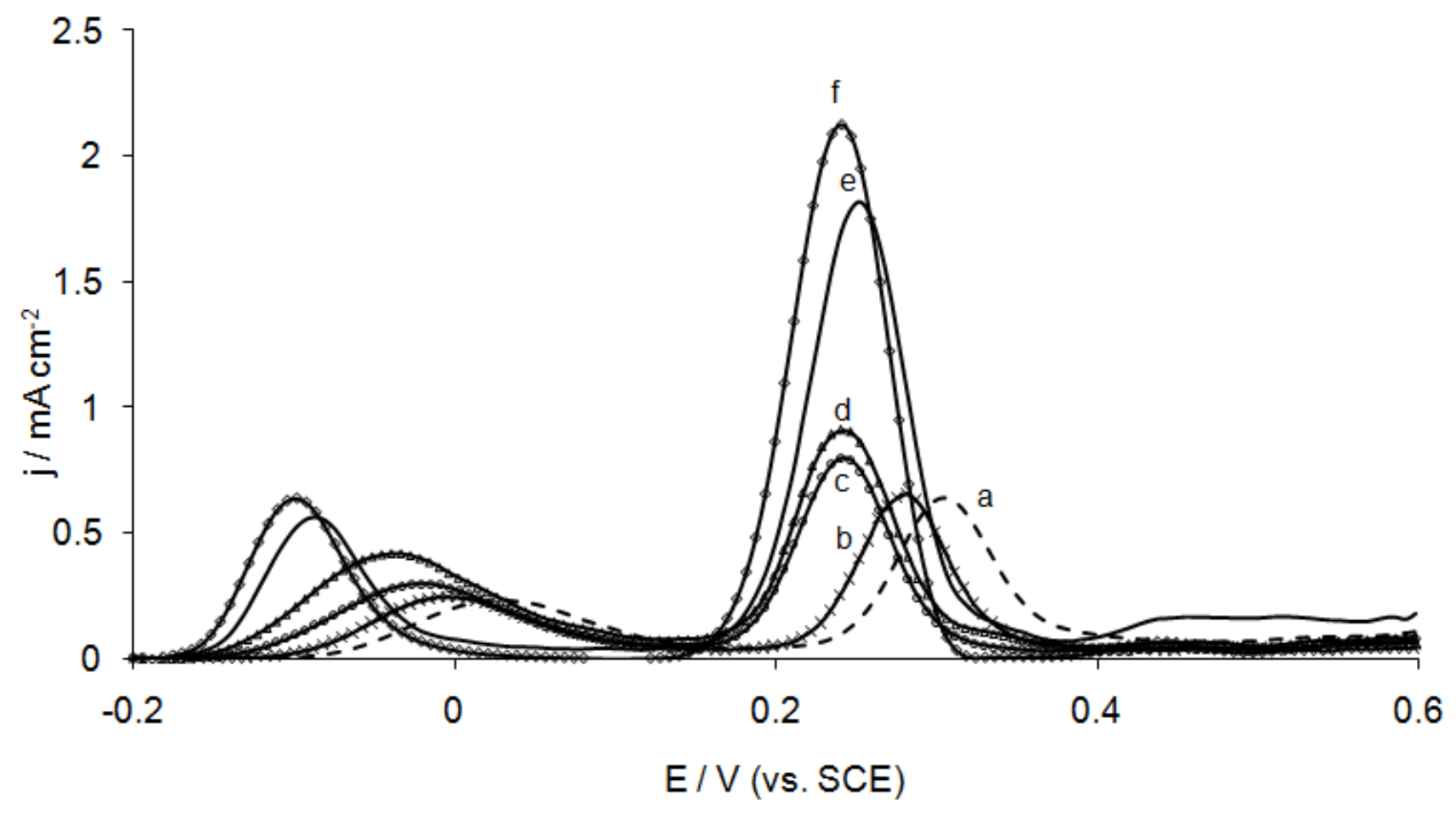

Figure 5. 


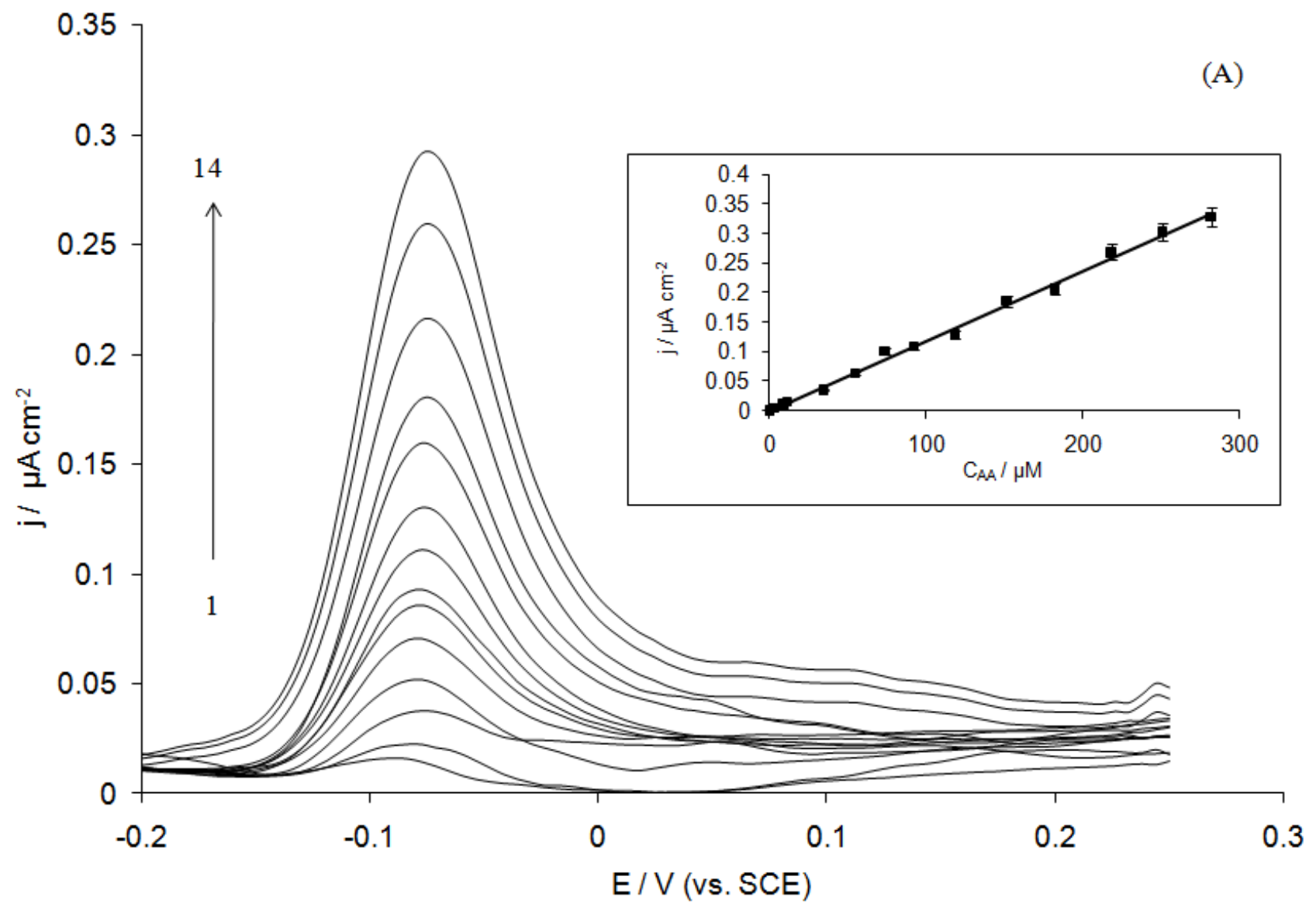

Figure 6A. 
(B)

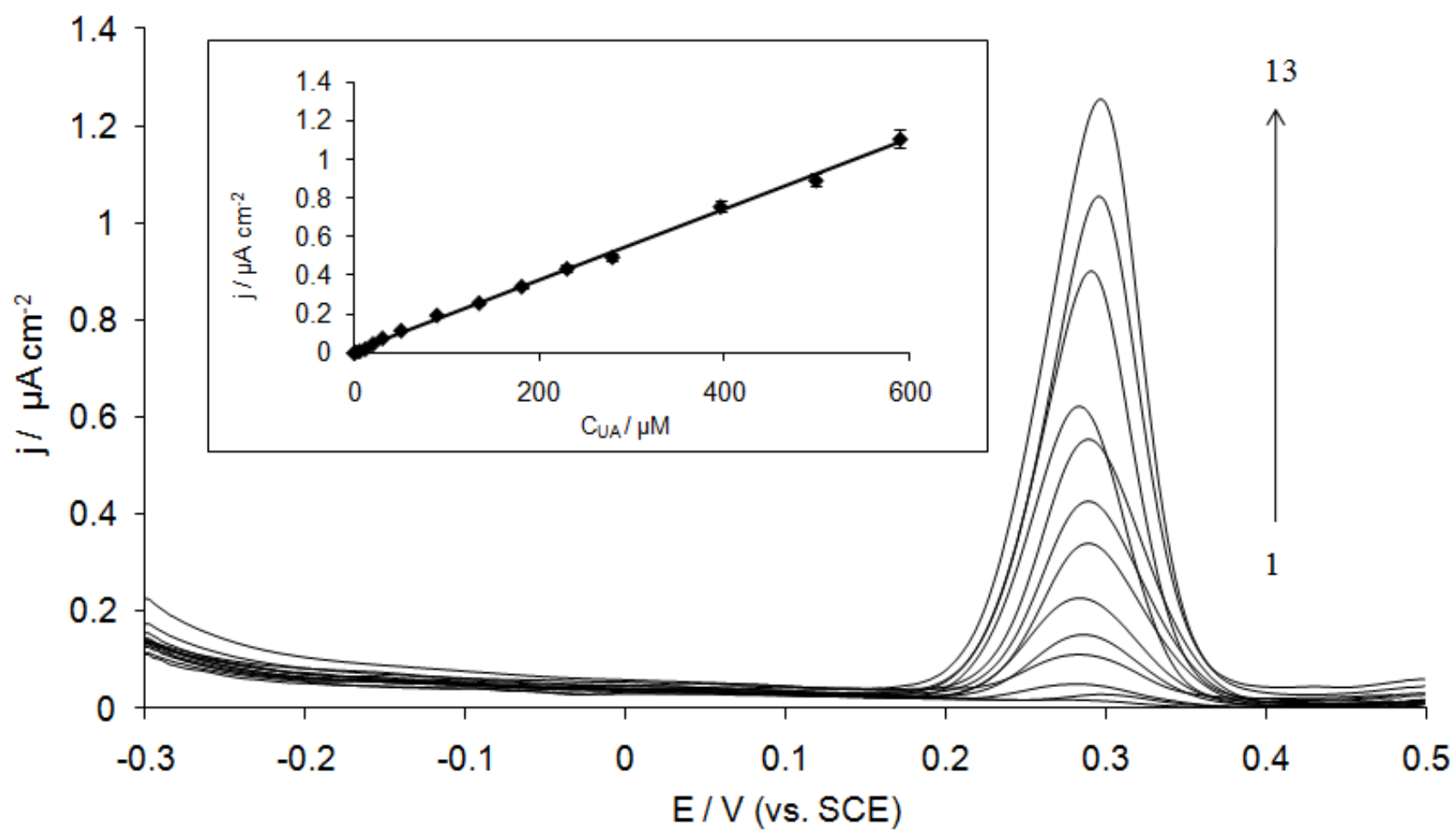

Figure 6B. 


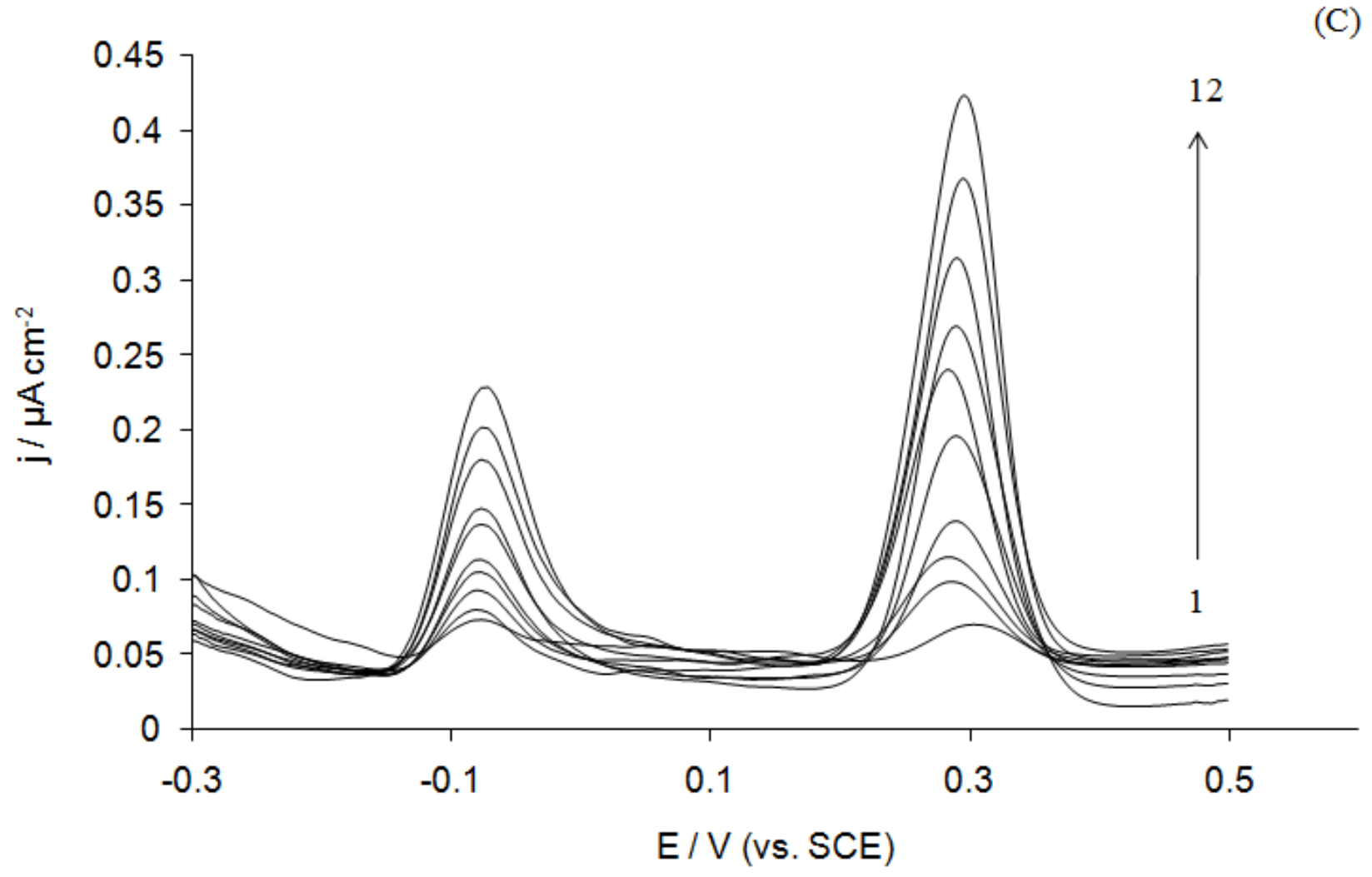

Figure 6C. 


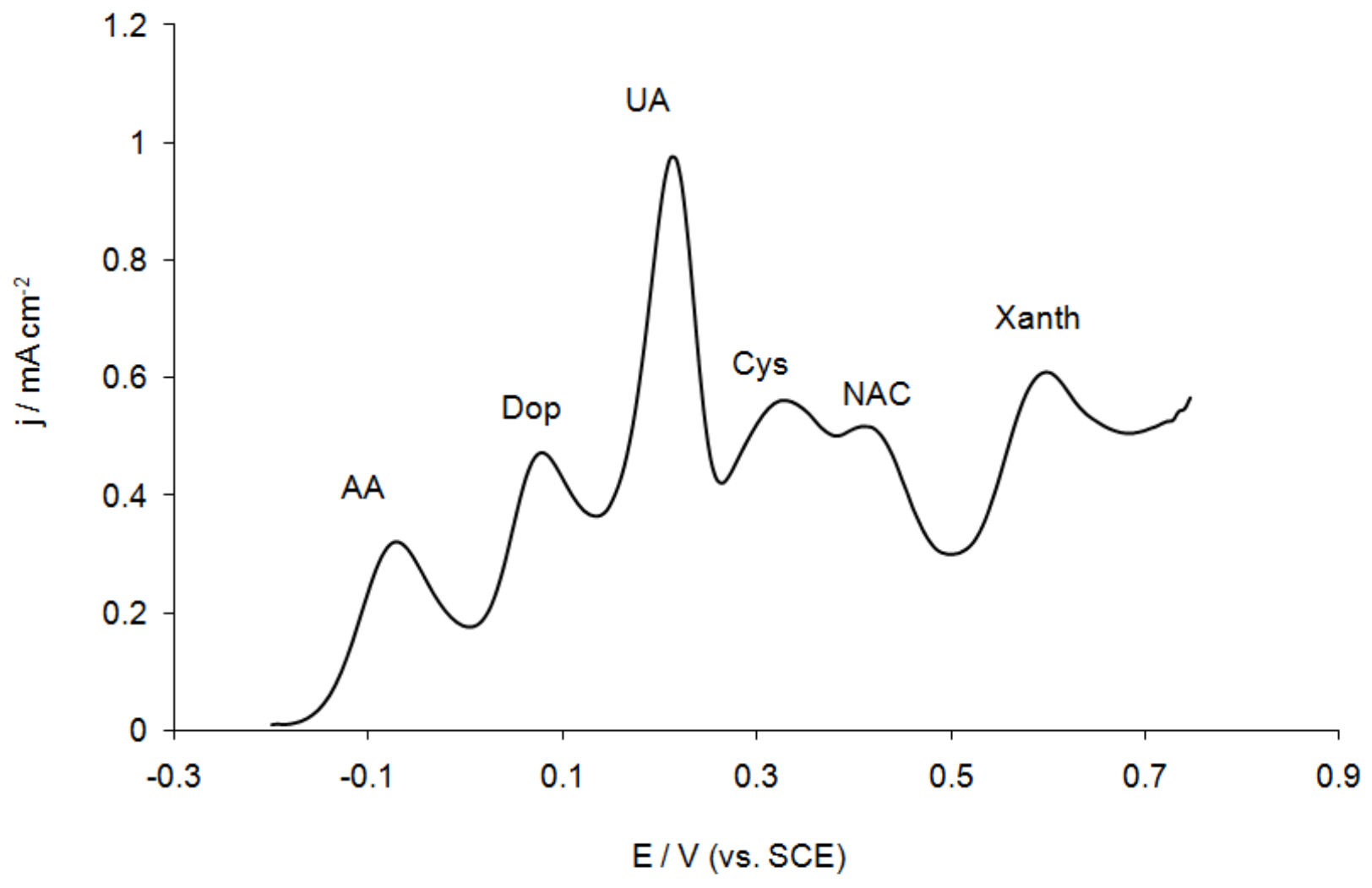

Figure 7. 


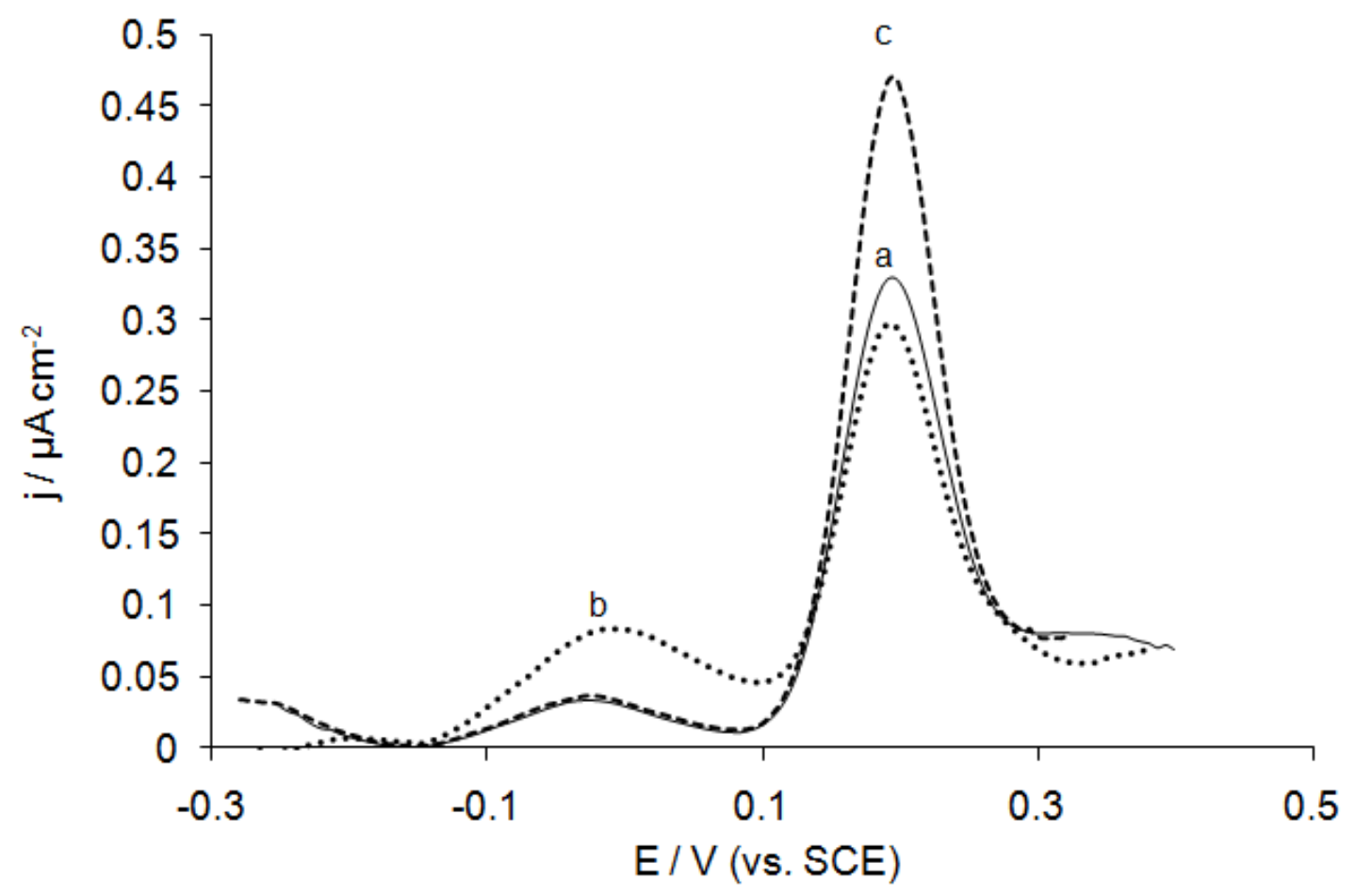

Figure 8. 